Research paper

\title{
In-situ investigation of dynamic deformation in NiTi shape memory alloys under laser induced shock
}

\author{
Xi Wang ${ }^{\mathrm{a}, *}$, Weiguang $\mathrm{Xia}^{\mathrm{b}}$, Xianqian $\mathrm{Wu}^{\mathrm{b}}$, Yanpeng Wei ${ }^{\mathrm{b}}$, Chenguang Huang ${ }^{\mathrm{b}}$ \\ a School of Mechanical, Electronic and Control Engineering, Beijing Jiaotong University, Beijing 100044, People's Republic of China \\ ${ }^{\mathrm{b}}$ Key Laboratory for Mechanics in Fluid Solid Coupling Systems, Institute of Mechanics, Chinese Academy of Sciences, Beijing 100190, People's Republic of \\ China
}

\section{A R T I C L E I N F O}

\section{Article history:}

Received 2 September 2016

Revised 23 May 2017

Available online 13 July 2017

\section{Keywords:}

Shape memory alloy

Laser induced shock

Martensitic transformation

Strain rate

Photonic doppler velocimetry

\begin{abstract}
A B S T R A C T
The free surface particle velocity of NiTi target shocked with a pulsed laser beam was measured with a photonic Doppler velocimetry (PDV) system to study the dynamic deformation behavior of NiTi alloys at ultra-high strain rate of $10^{6} \sim 10^{7} / \mathrm{s}$. Through the analysis of the particle velocity profiles, the shock wave intensity was found to have the influence on the process of austenite-martensite transformation. Theoretical analysis of shock wave propagation showed that the first plateau in the velocity profile was caused by martensitic transformation and the second plateau if existing is caused by the subsequent plastic yielding of shock induced martensite. Residual martensite of the NiTi, which exhibited as needlelike structures, was observed in the laser shocked region. Based on the present results, and the studies by Nemat-Nasser et al. (2005), Liao et al. (2012), and Wang et al. (2013), we concluded that laser induced shock can cause the martensitic transformation as long as the laser induced shock pressure reaches a critical value. The dynamic transition stress and the dynamic tensile strength of NiTi alloys were also determined from the experimentally measured surface velocity profile.
\end{abstract}

(C) 2017 Elsevier Ltd. All rights reserved.

\section{Introduction}

As one of the most popular active materials, NiTi shape memory alloys (SMAs) have been widely used in medical and structural applications due to their unique properties such as shape memory and superelastic effects (Otsuka and Wayman, 1999). Both of the two characteristics are related to the phase transformation between the high temperature phase with $\mathrm{CsCl}$ structure (B2) and the low temperature phase with monoclinic structure (B19') (Otsuka and Ren, 2005). It is well known that martensitic transformation can be induced by temperature and stress. Martensitic transformation is also sensitive to the strain rate (Nemat-Nasser and Choi, 2005; Nemat-Nasser et al., 2005). Laser induced shock is a newly developed method to deform the metallic material at ultra-high strain rates (Ding and Ye, 2006; Lin et al., 2015; Montross et al., 2002; Peyre and Fabbro, 1995). In the laser shock process, a shock wave with high amplitude and short duration is generated through rapid expansion of high-temperature plasma induced by the interaction of a pulsed high-intensity laser beam and an absorption layer on the metallic target surface. If the amplitude of the laser induced shock pressure exceeds the Hugoniot

\footnotetext{
* Corresponding author. Tel./fax: +86 1051683195.

E-mail address: wangxi@bjtu.edu.cn (X. Wang).
}

elastic limit (HEL) of the material, plastic deformation occurs and dense of dislocations are generated, resulting in residual compressive stress near the surface of target material. The induced peak pressure can reach a level of several GPa and the pressure duration is at the nanosecond time scale. Thus the strain rate during the laser shock process can be as high as $10^{6} \sim 10^{7} / \mathrm{s}$. Using laser induced shock loading, Liao et al. (2012) observed residual deformation induced martensite in the shocked region of an austenite NiTi alloy, which indicated that martensitic transformation occurred at ultra-high strain rate $\left(10^{6} \sim 10^{7} / \mathrm{s}\right)$. The study by Wang et al. (2013) showed that there was amorphization near the laser shock treated surface in an austenite NiTi target and no residual martensite was observed. This indicates that the existing literature on ultra-high strain rate behavior of NiTi alloys has controversy. Although the results of the aforementioned studies provide some important information on the microstructure evolution for NiTi alloys after laser induced shock, the dynamic behavior of NiTi alloys during the shock loading remains unclear. The ultrahigh strain rate response of NiTi alloys needs more in-situ experimental investigation to clarify those issues.

The investigation of dynamic behavior of material under laser induced shock needs a better understanding of the shock wave propagation and the dynamic response of target materials. The target material deforms under high pressure and ultra-high strain rate 


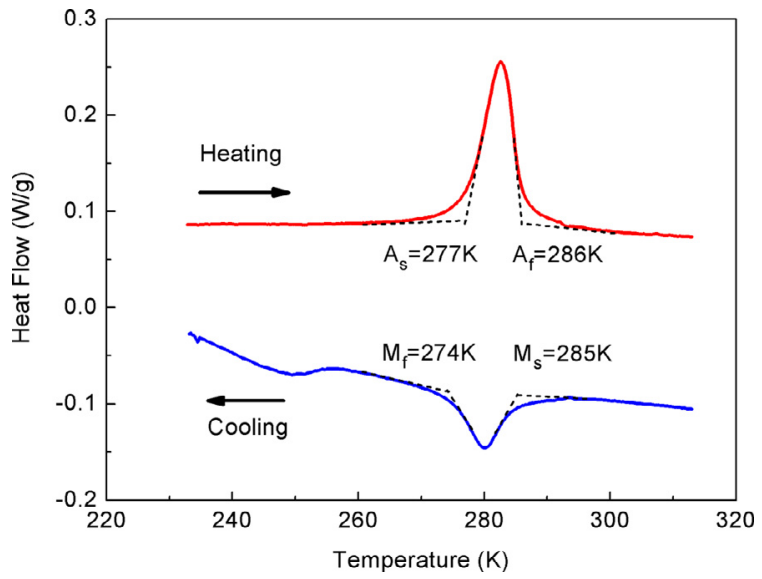

Fig. 1. Differential scanning calorimetery (DSC) curves of as-received NiTi alloy.

during laser induced shock loading and in-situ shock diagnostic techniques with high time resolution are required. Recently developed photonic Doppler velocimetry (PDV) technique has been widely used for tracking fast-changing velocity on short time scales and becomes a promising diagnostics for shock physics experiments (Dolan, 2010; Dolan and Jones, 2007; Strand et al., 2006). The particle velocity at the back free surface contains a lot of information about the wave propagation and dynamic response of target materials. Using the wave theory, the characteristics of dynamic mechanical response of austenite NiTi alloy, such as flow stress, dynamic transition stress, and dynamic tensile strength, can be determined from the measured surface velocity.

In this paper, we report an in-situ study of the dynamic behavior of NiTi alloys under laser induced shock using the PDV technique. By analyzing the measured particle velocity at the back free surface, we concluded that martensitic transformation can be triggered during the laser induced shock loading if the peak pressure reaches a critical peak pressure. The dynamic transition stress and the dynamic tensile strength of the NiTi alloys were also obtained from the PDV measurement results.

\section{Experimental procedures}

\subsection{Materials}

The NiTi materials used in this study were purchased from GEE Shape Memory Alloy Inc. (Beijing, China), with the nominal composition of $\mathrm{Ni}-50.9 \%$ and $\mathrm{Ti}-49.1 \%$ (at. \%). Differential scanning calorimetery (DSC, Perkin Elmer Diamond system) was carried out between $223 \mathrm{~K}$ and $323 \mathrm{~K}$ with a heating and cooling rate of $10 \mathrm{~K} / \mathrm{min}$ to determine the transformation temperatures. As shown in Fig. 1, the austenite start $\left(A_{s}\right)$ and finish temperature $\left(A_{f}\right)$ were $277 \mathrm{~K}$ and $286 \mathrm{~K}$, respectively, while the martensite start $\left(M_{S}\right)$ and finish temperature $\left(M_{f}\right)$ were $285 \mathrm{~K}$ and $274 \mathrm{~K}$, respectively. Thus the as-received NiTi alloy is in austenite phase and exhibits superelastic behavior under stress at room temperature (Otsuka and Wayman, 1999). The NiTi sheets were cut into disks with the diameter of $10 \mathrm{~mm}$ and thickness of about $1 \mathrm{~mm}$. Before the laser shock experiments, the shocked surface of the targets was ground using a sequence of increasing grit sandpaper followed by a final polishing process with $50 \mathrm{~nm} \mathrm{SiO}{ }_{2}$ suspension liquid, while the back free surface was ground by 400 grit sandpaper to enhance the signalnoise ratio of PDV measurement (Wu et al., 2014).

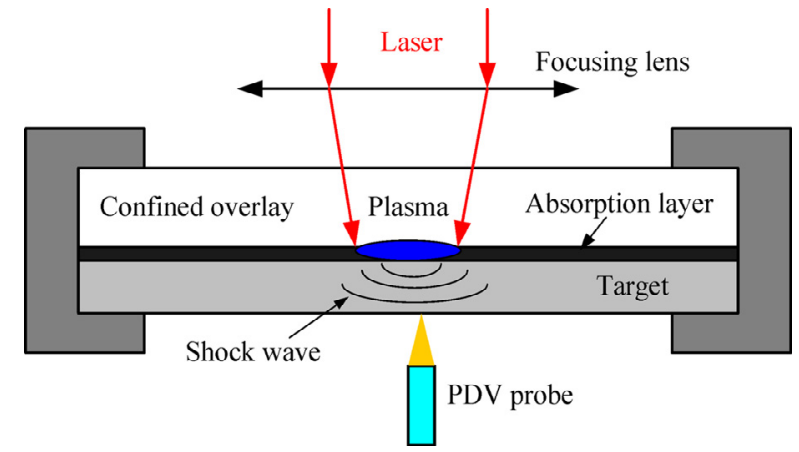

Fig. 2. The schematic of laser shock experiment.

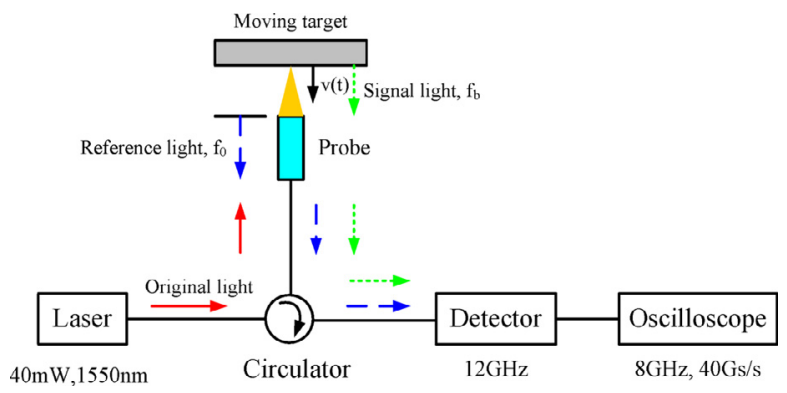

Fig. 3. Configuration of the PDV system.

\subsection{Laser shock experiment}

Fig. 2 shows the schematic of the laser shock experiments. The shocked surface of each target was firstly covered with a $40 \mu \mathrm{m}$ thick aluminum foil as an absorption layer, and then confined with a $4 \mathrm{~mm}$ thick BK7 glass against the laser irradiation. The BK7 glass is fully clamped with the target by a specially designed fixture. The laser pulse was delivered by a Q-switched Nd: YAG pulse laser (Spectra Physics-Quanta Ray) with a wavelength of $1064 \mathrm{~nm}$. The energy of single laser pulse is about $2.4 \mathrm{~J}$ and the pulse duration (full width at half maximum, FWHM) is approximately $10 \mathrm{~ns}$. A focusing lens was used to adjust the beam diameter to obtain various laser power densities. The laser power densities irradiated at the target surface varied from $2.6 \mathrm{GW} / \mathrm{cm}^{2}$ to $4.4 \mathrm{GW} / \mathrm{cm}^{2}$ in this study.

\subsection{PDV system}

During the pulse laser irradiation, the particle velocity of the target back free surface was measured simultaneously with a PDV system as illustrated in Fig. 3. The construction of the PDV system can be found elsewhere (Jensen et al., 2007; Song et al., 2012; Wu et al., 2014). When the laser travels through the circulator, a portion of light is reflected, acting as the reference light with the original frequency, $f_{0}$. The other portion of light irradiates the moving target surface and Doppler frequency shift will be generated due to the Doppler effect. Both the reference light with original frequency, $f_{0}$, and the signal light with Doppler-shifted frequency, $f_{b}$, are collected with the detector. A detecting system with a high bandwidth is used to record the difference in the two frequencies, i.e., the beat frequency, $\bar{f}_{b}(t)$. The velocity of the moving target surface can be obtained as

$v(t)=\frac{\lambda_{0}}{2} \bar{f}_{b}(t)$

where $\lambda_{0}$ is the original wavelength of the incident laser. 


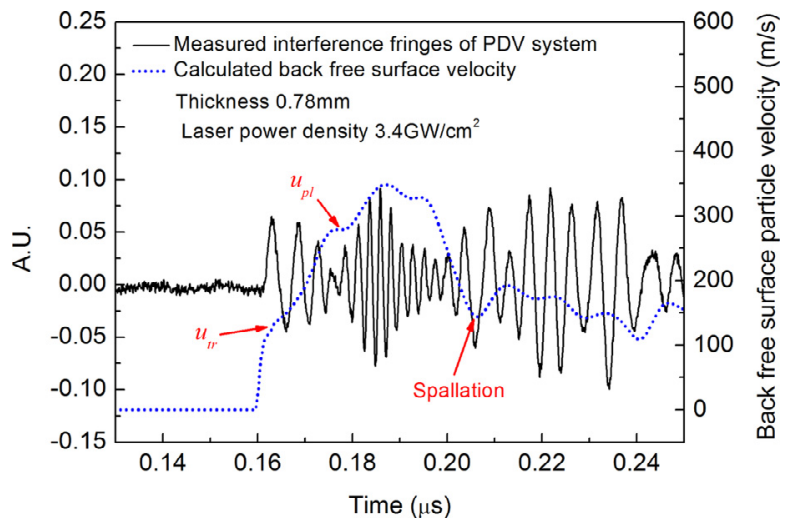

Fig. 4. Interference fringes measured by the PDV system and corresponding back free surface velocity profile for laser power density $3.4 \mathrm{GW} / \mathrm{cm}^{2}$.

\subsection{Microstructure characterization}

Optical microscopy (55XA, Shanghai, China) was used to characterize the microstructure of the shocked surface after laser shock process.

\section{Results and discussion}

\subsection{Martensitic transformation behavior}

\subsubsection{PDV results}

The typical heterodyne fringe measured at the back free surface of shocked NiTi target material with the PDV system and the calculated surface particle velocity are shown in Fig. 4. The laser power density for this test is $3.4 \mathrm{GW} / \mathrm{cm}^{2}$. According to the measurement principle of the PDV (Jensen et al., 2007; Wu et al., 2014), the instantaneous velocity is proportional to the heterodyne frequency, $\bar{f}_{b}(t)$. Thus the density of heterodyne fringes indicates the magnitude of the particle velocity. It is to be noted that the amplitude of the heterodyne fringes changes with time, which is ascribed to the PDV measurement principle that both the frequency and the amplitude of the beat fringes are functions of particle velocities (Jensen et al., 2007; Wu et al., 2014). At about 159 ns, the particle velocity begins to increase, indicating the elastic wave reaches the back free surface at this time. At $162 \mathrm{~ns}$, there exists a velocity plateau $\left(u_{t r}\right)$ at a level of $121.5 \mathrm{~m} / \mathrm{s}$. With further loading, another velocity plateau $\left(u_{p l}\right)$ at a level of $277.8 \mathrm{~m} / \mathrm{s}$ was observed at about $175 \mathrm{~ns}$. At about $187 \mathrm{~ns}$, the surface particle velocity reaches the peak value of about $348.6 \mathrm{~m} / \mathrm{s}$, indicating that the first shock wave reaches the back surface. It is interesting to note that the particle velocity profile shows two plateaus during the shock loading, which is quite different from that of plastically deformed metallic materials (Song et al., 2012; Wu et al., 2011). With the decreasing of shock pressure, the NiTi material is unloaded by release waves and the surface particle velocity begins to decrease. During the unloading, spallation could happen if the tensile stress exceeds the dynamic tensile strength of the material. As shown in Fig. 4, the surface particle velocity starts to rise again at about $206 \mathrm{~ns}$ indicating a spallation beneath the back surface of the target material for this laser power density.

Experiments were conducted at three different laser power densities and the free surface particle velocity results are shown in Fig. 5. The free surface velocity profile of specimen treated with laser power density 3.4 or $4.4 \mathrm{GW} / \mathrm{cm}^{2}$ shows two velocity plateau during laser induced shock loading and spallation during the unloading, while the one treated with laser power density $2.6 \mathrm{GW} / \mathrm{cm}^{2}$ has only one velocity plateau and no spallation.

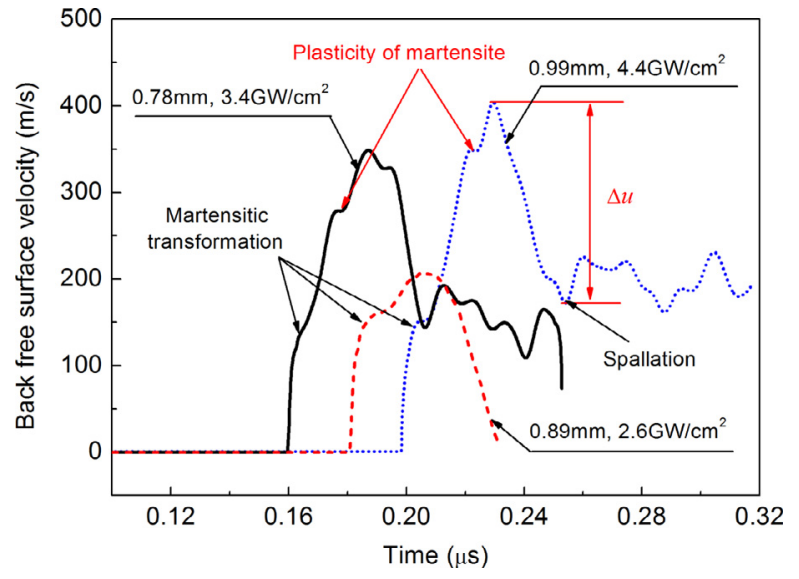

Fig. 5. Velocity profile of NiTi target at different laser power density.

The experimental parameters, measured quantities, and calculated quantities are summarized in Table 1 . The sample thickness $(L)$, and the laser power density $\left(I_{0}\right)$ are shown in columns $2-3$, respectively. The time of elastic wave arriving at the back free surface $(\Delta t)$ is listed in column 4 . The elastic longitudinal sound speed $\left(C_{L}^{e}\right)$ was obtained by dividing the sample thickness with the arriving time of elastic wave and is listed in column 5. The average elastic longitudinal sound speed for all three tests is estimated to be $4.95 \mathrm{~km} / \mathrm{s}$. The first velocity plateau $\left(u_{t r}\right)$, the second velocity plateau $\left(u_{p l}\right)$, and the maximum particle velocity $\left(u_{m}\right)$ obtained from the free surface particle velocity profiles in Fig. 5 are listed in columns $6-8$, respectively. The pull-back velocity $(\Delta u)$, defined as the difference between the maximum particle velocity and the minimum particle velocity of the spallation signal, as indicated in Fig. 5, is shown in columns 9 . The pull-back velocity $(\Delta u)$ is used to calculate the dynamic tensile strength of the material, and will be discussed in detail later. The peak pressures $\left(p_{m}\right)$ induced by laser pulse for different laser power densities are given in column 10. The peak pressure was estimated by the Fabbro's model (Fabbro et al., 1990),

$p_{m}(G P a)=0.01 \sqrt{\alpha /(2 \alpha+3)} \sqrt{Z\left(g^{\left.-2 m^{-2} s^{-1}\right)}\right.} \sqrt{I_{0}\left(G W c^{-2}\right)}$

where $\alpha$ is the fraction of absorbed energy contributed by the thermal energy $(\alpha=0.25), I_{0}$ is the laser power density and $Z\left(2 / Z=1 / Z_{1}+1 / Z_{2}\right)$ is the reduced shock impedance between the confining layer (BK-7, shock impedance $1.44 \times 10^{6} \mathrm{~g} \mathrm{~cm}^{-2} \mathrm{~s}^{-1}$ ) and the absorption material (Al, shock impedance $\left.1.47 \times 10^{6} \mathrm{~g} \mathrm{~cm}^{-2} \mathrm{~s}^{-1}\right)$. The shock pressure transmitted into the NiTi material is enlarged due to the impedance mismatch between the target material (NiTi, shock impedance $3.44 \times 10^{6} \mathrm{~g} \mathrm{~cm}^{-2} \mathrm{~s}^{-1}$ ) and the absorption material (Millett and Bourne, 2004). The peak pressure generated by laser induced shock varies from 7.5 to $10.0 \mathrm{GPa}$ for laser power densities from 2.6 to $4.4 \mathrm{GW} / \mathrm{cm}^{2}$.

\subsubsection{Microstructure}

After the laser shock experiment, the laser irradiated surface of the shocked specimen was examined with optical microscope and the micrographs are shown in Fig. 6. It can be seen that the specimen treated with laser power density $2.6 \mathrm{GW} / \mathrm{cm}^{2}$ did not show any obvious feature of deformation and the shocked surface was as smooth as the untreated specimen as shown in Fig. 6(a)-(b). In contrast, dense of needlelike structures of deformation induced martensites were introduced in the shocked region for specimen treated with laser power density 3.4 and $4.4 \mathrm{GW} / \mathrm{cm}^{2}$ as shown in Fig. 6(c) and (e). The higher magnification micrographs taken from the circled regions in Fig. 6(c) and (e) are shown in Fig. 6(d) and 
Table 1

Relevant experimental parameters and calculated quantities.

\begin{tabular}{|c|c|c|c|c|c|c|c|c|c|c|c|}
\hline No. & $L(\mathrm{~mm})$ & $I_{0}\left(\mathrm{GW} / \mathrm{cm}^{2}\right)$ & $\Delta t(\mu \mathrm{s})$ & $C_{L}^{e}(\mathrm{~mm} / \mu \mathrm{s})$ & $u_{t r}(\mathrm{~m} / \mathrm{s})$ & $u_{p l}(\mathrm{~m} / \mathrm{s})$ & $u_{m}(\mathrm{~m} / \mathrm{s})$ & $\Delta u(\mathrm{~m} / \mathrm{s})$ & $p_{m}(\mathrm{GPa})$ & $\sigma_{s}^{A M, d y n}(\mathrm{MPa})$ & $\sigma_{b}(\mathrm{GPa})$ \\
\hline Test-1 & 0.89 & 2.6 & 0.180 & 4.94 & 150.2 & - & 206.8 & - & 7.5 & 1217 & - \\
\hline Test-2 & 0.78 & 3.4 & 0.159 & 4.91 & 121.5 & 277.8 & 348.6 & 204.8 & 8.6 & 984 & 2.66 \\
\hline Test-3 & 0.99 & 4.4 & 0.198 & 5.00 & 149.1 & 350.3 & 403.4 & 230.8 & 10.0 & 1208 & 3.00 \\
\hline
\end{tabular}

(f), respectively, to reveal the detailed microstructures of needlelike martensites.

\subsubsection{Analysis}

The dynamic behavior of NiTi alloys is sensitive to strain rates, and whether martensitic transformation happens at ultrahigh strain rates of $10^{6} \sim 10^{7} / \mathrm{s}$ is not clear. Based on the Hopkinson bar tests, Nemat-Nasser et al. (2005) reported martensitic transformation would not occur if the strain rate was higher than a critical strain rate of about $10^{4} / \mathrm{s}$. Liao et al. (2012) obtained the evidence of martensitic transformation during laser shock process using the TEM and XRD characterizations of postmortem specimen. Our previous study showed that there is only amorphization near the laser shock treated surface in an austenite NiTi target and no residual martensite was observed (Wang et al., 2013). In the present study, the microscopic observation of shocked region showed the evidence of residual martensites for laser power density $3.4 \mathrm{GW} / \mathrm{cm}^{2}$ and $4.4 \mathrm{GW} / \mathrm{cm}^{2}$ but no any sign of residual martensites for laser power density $2.6 \mathrm{GW} / \mathrm{cm}^{2}$ (see Fig. 6). Correspondingly, the measured free surface particle velocity profiles showed the difference in terms of the number of velocity plateau (see Fig. 5). That means the measured in-situ wave propagation behavior, i.e. the free surface particle velocity profile, can be related to dynamic deformation behavior of NiTi alloys under laser shock loading.

According to the studies by Song et al. (2012) and Wu et al. (2011), for typical plastically deformed metals such as aluminum alloys, there is only one plateau in the rising period of particle velocity due to the elastic precursor wave. The wave propagation in phase change material is quite different from the traditional plastically deformed material. Jensen et al. (2009) used a velocity interferometer (VISAR) to measure the particle velocity of iron during plate impact experiments. The results showed two plateaus during the rising period of the particle velocity, providing the evidence that iron transformed from the alpha (bcc) phase to the epsilon (hcp) phase when the compressed pressure was higher than 13 GPa. Jensen et al. (2009) explained that the appearance of two plateaus was the result of formed three-wave structure in the shocked material, consisting of an elastic wave, a P1 wave (plastic wave), and a P2 wave (phase transforming wave). Similarly, our results of two plateaus in velocity profile as shown in Figs. 4 and 5 is also caused by a three-wave structure but it will be shown below that the sequence of the three-wave structure of NiTi alloy in the present study is different from that of iron.

When the shock wave propagates in the phase change material and plastically deformed metallic material, different characteristics will be shown in the back free surface particle velocities. Here a simplified theoretical analysis of wave propagation in phase change material is given. Since the spatial domain of laser is nearly flat and the focal diameter of laser beam $(3.0 \sim 4.0 \mathrm{~mm})$ is large enough compared to the thickness of the NiTi alloy target $(\sim 1.0 \mathrm{~mm})$, the loading status of the target material can be approximately considered as uniaxial strain condition. The constitutive model of NiTi SMAs is shown in Fig. 7 (Otsuka and Ren, 2005; Otsuka and Wayman, 1999; Wang et al., 2013). For an austenite NiTi alloy, phase transformation from austenite to martensite occurs when the applied stress reaches the phase transition stress $\left(\sigma_{s}^{A M}\right)$. Elastic deformation of the induced martensite occurs during further loading until the loading stress reaches the yield stress of the martensite
$\left(\sigma_{y}^{M}\right)$. During unloading, the material responds elastically until the stress reaches the transition stress of reverse transformation $\left(\sigma_{s}^{M A}\right)$. The recovered austensite deforms elastically with further unloading.

During unloading, the elastic wave, the plastic wave, the reverse transformation wave, and the release wave interact with each other. Thus it is difficult to obtain a theoretical solution for unloading process. Here, only the wave propagating behavior and free surface particle velocity profile during loading are analyzed. As shown in Fig. 8, when the laser induced shock waves interact with SMAs, austenite elastic wave propagates into the target. Transformation wave will be generated when the applied stress reaches the phase transition stress of martensitic transformation, $\sigma_{s}^{A M}$. When the applied stress exceeds the finish stress of martensitic transformation, the austenite to martensite transformation is finished and the material is in fully martensite phase. Martensite elastic wave is then generated with continuous loading. As the martensite elastic wave speed is faster than the transformation wave speed, the martensite elastic wave will catch up and interact with the transformation wave. According to Dai et al. (2004), the interaction between martensite elastic wave and phase transformation wave can yield complex wave patterns in $\mathrm{x}$-t diagram, where the slope will increase slowly and consequently result in the first plateau, denoted as $u_{t r}$, of the back free surface velocity history as depicted in Fig. 8. When the applied stress reaches the yield stress of the martensite $\sigma_{y}^{M}$, plastic wave is generated and propagates into the target. Another plateau, denoted as $u_{p l}$ as shown in Fig. 8, will appear due to the speed difference between the martensite elastic wave and martensite plastic wave. When the applied load reaches its peak, $p_{m}$, the free surface particle velocity will also reach its maximum value, denoted as $u_{m}$. According to the analysis, for phase change materials like NiTi SMAs, there will be two velocity plateaus in the rising period of free surface particle velocity corresponding to the martensitic transformation and plastic deformation of martensite, respectively. Note that there might be another reason leading to the formation of two plateaus during the rising period of free surface particle velocity for some metals with high enough elastic precursor. In this scenario, the first plateau is caused by an elastic precursor wave because of the plasticity of material, and the second plateau is caused by interaction between the reflection of the elastic wave (elastic precursor) from the back free surface and the plastic wave induced by the loading. Using moving window molecular dynamics simulation, Zhakhovsky et al. (2012) reported a two-zone elastic-plastic shock wave structure for materials with high elastic wave amplitudes, resulting in two velocity plateaus in the particle velocity profile during loading. Note that if the two-zone, elastic-plastic shock wave structure forms in the NiTi, the deformation mechanism should be direct dislocation-induced plastic slip of austenite of NiTi. In that case, no residual martensite will be seen after laser shock process. However, the residual martensites were clearly observed in shocked region as shown in Fig. 6. Therefore, the three-wave structure of NiTi SMAs during laser shock process consists of an elastic wave, a transformation wave, and a plastic wave as discussed in Fig. 8.

As shown in Fig. 5, there is only one plateau in the free surface particle velocity profile for laser power density $2.6 \mathrm{GW} / \mathrm{cm}^{2}$ 


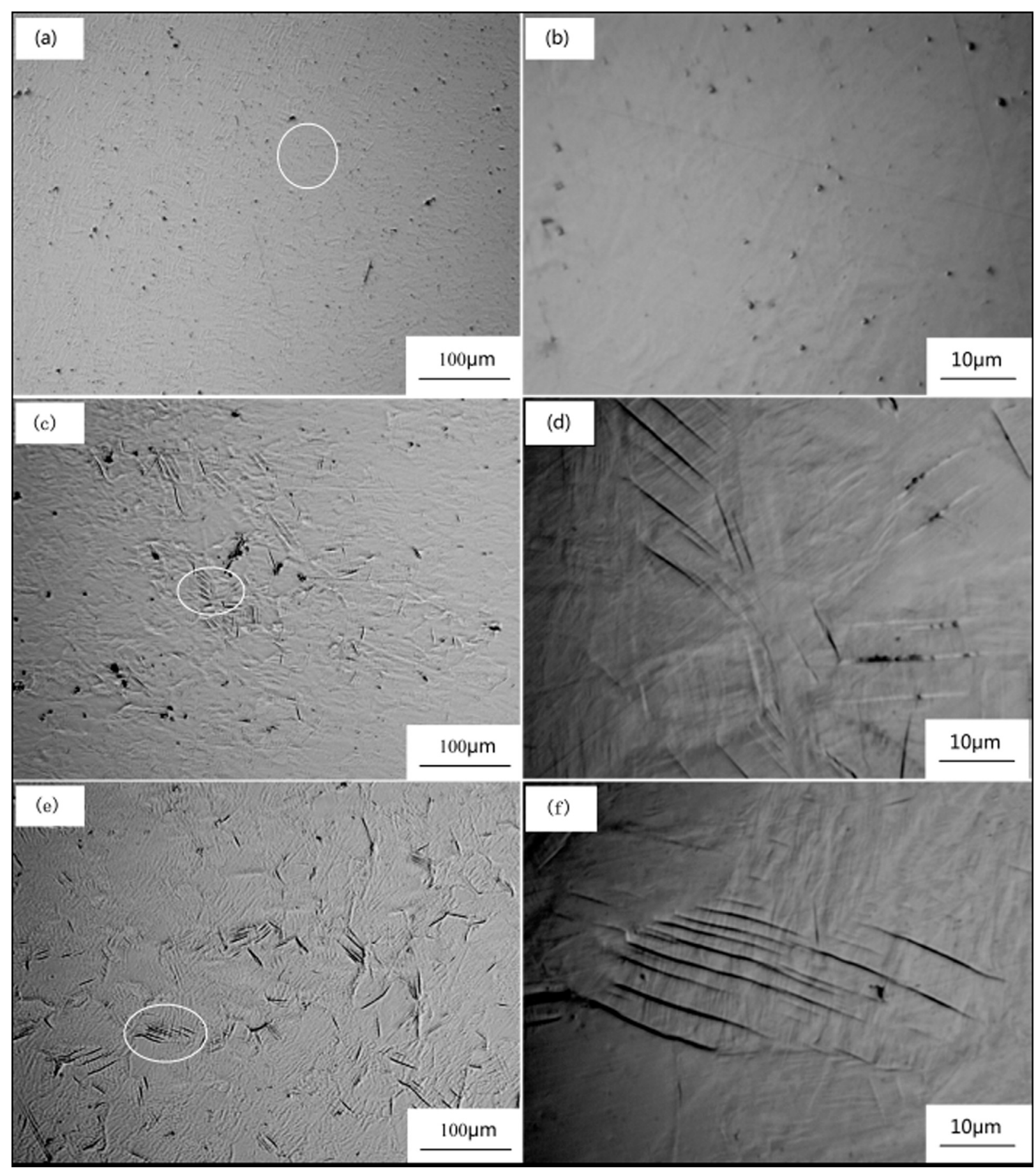

Fig. 6. Optical micrographs of the laser shocked surface. (a)-(b) $2.6 \mathrm{GW} / \mathrm{cm}^{2}$. (c)-(d) $3.4 \mathrm{GW} / \mathrm{cm}^{2}$. (e)-(f) $4.4 \mathrm{GW} / \mathrm{cm}^{2}$.

(the corresponding peak pressure is $7.5 \mathrm{GPa}$ ). The optical observation of shocked surface shows no any residual martensites and also no any features of residual deformation which indicates no plastic deformation of NiTi (see Fig. 6a-b). When the peak pressure is higher than the martensite transition stress but lower than the yield stress of martensite, martensitic transformation occurs during loading, while no plasticity of martensite happens. During unloading, the transformation deformation is completely recovered due to the superelastic effect of NiTi SMAs. As a result, the dynamic deformation is fully recovered and no residual deformation of NiTi is induced after laser shock process. Thus the deformation mechanism is mainly martensitic transformation for the speci- men treated with laser power density $2.6 \mathrm{GW} / \mathrm{cm}^{2}$. From this point, the deformation mechanism depends on the laser power density, e.g. the peak pressure of laser induced shock wave. According to Wang et al. (2013), no residual deformation induced martensite was observed in the same NiTi alloy material during the laser shock process while using water as the confining overlay, where the peak pressure of laser induced shock wave varied from 3.9 to $4.5 \mathrm{GPa}$, and the deformation mechanism was controlled mainly by the dislocation-induced plastic slip of austenite and amorphization. Therefore, it could be concluded that there exists a critical pressure to induce martensitic transformation under laser induced shock. The critical peak pressure is in the range of $4.5 \mathrm{GPa}$ to $7.5 \mathrm{GPa}$. 


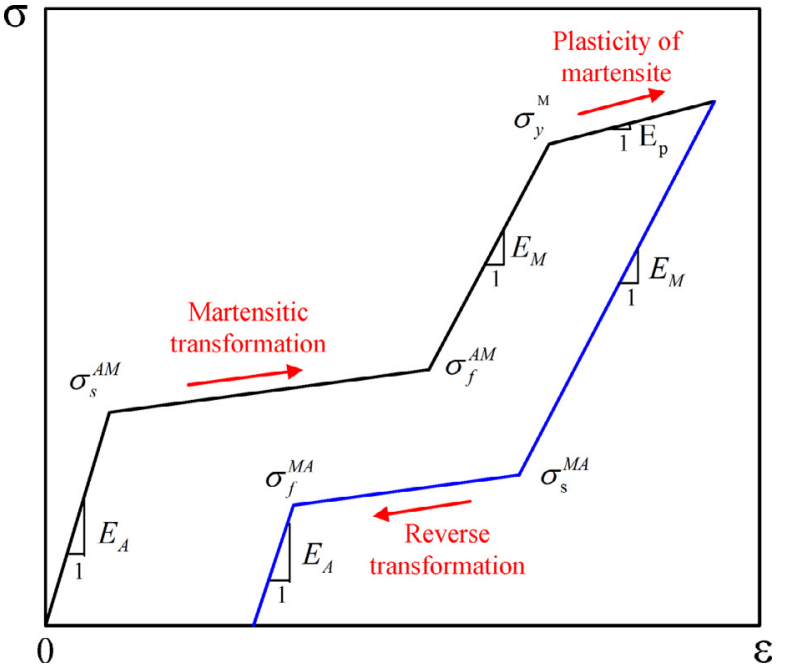

Fig. 7. The constitutive model of NiTi SMAs.

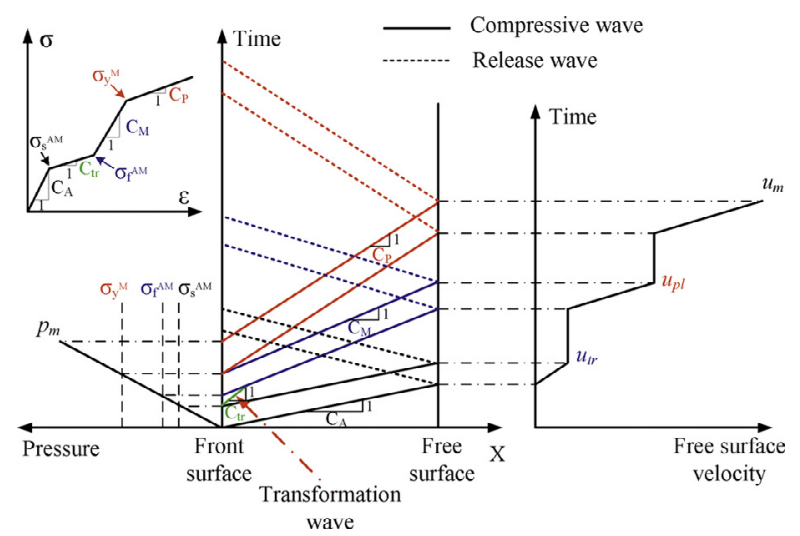

Fig. 8. Shock wave propagation analysis and resulted free surface velocity profile of SMAs in laser shock process.

Since the shock pressure was only at the level of $2 \mathrm{GPa}$ in the study of Nemat-Nasser et al. (2005), which was much lower than the critical peak pressure, the austenite phase deforms by direct dislocation-induced plastic slip instead of transforming to martensite. In addition, the peak pressure was as high as $7.8 \mathrm{GPa}$ in the study of Liao et al. (2012), therefore the martensitic transformation occurred at ultra-high strain rate and residual martensites was observed in the postmortem specimen. Our results reveal the existence of critical peak pressure in dynamic behavior of NiTi alloys and clarify the controversy in the literature. More experiments will be conducted to determine this critical peak pressure more accurately in the future.

\subsection{Dynamic transition stress}

The dynamic transition stress $\left(\sigma_{s}^{A M, d y n}\right)$ can be calculated from the first plateau in particle velocity profile $\left(u_{t r}\right)$ as shown in column 11 of Table 1. According to the Rankin-Hugoniot relations (Meyers, 1994), for an infinite thick target in the uniaxial strain state, the compressive shock pressure, $p$, can be written as

$p=\rho_{0} C_{L}^{e} u, p<\mathrm{HEL}$

where $\rho_{0}=6.45 \mathrm{~g} / \mathrm{cm}^{3}$ is the NiTi material density, $C_{L}^{e}$ is the elastic longitudinal sound speed ( $C_{L}^{e}=4.95 \mathrm{~km} / \mathrm{s}$ determined in this study), and $u$ is the particle velocity and equal to one half of the measured surface velocity. HEL is the Hugoniot elastic limit and can be cal- culated as,

$H E L=\rho_{0} C_{L}^{e} \frac{u_{t r}}{2}$

As the martensitic transformation is often described by the generalized plasticity theory (Bouvet et al., 2004; Kan et al., 2010; Lubliner and Auricchio, 1996), the behavior of martensitic transformation is similar to the plasticity of materials. So the conception of HEL is also used during the martensitic transformation process. In this way, transition stress of phase change materials is equivalent to the yield stress of plastically deformed metallic materials. According to Johnson and Rhode (1971), HEL is proportional to the dynamic yield strength of the material. Thus, for phase change materials, the dynamic transition stress $\left(\sigma_{s}^{A M, d y n}\right)$ can be expressed as,

$H E L=\frac{1-v}{1-2 v} \sigma_{s}^{A M, d y n}$

where $v=0.33$ is the Poisson's ratio. Combining Eqs. (4) and (5), the $\sigma_{s}^{A M, d y n}$ can be calculated through $u_{t r}$.

The dynamic transition stress $\left(\sigma_{s}^{A M, d y n}\right)$ is shown in column 11 of Table 1 . The dynamic transition stress $\left(\sigma_{s}^{A M, d y n}\right)$ can be as high as $1.0 \mathrm{GPa}$ under the laser induced shock loading where the strain rate is in the range of $10^{6} / \mathrm{s}$ to $10^{7} / \mathrm{s}$. Our previous work (Wang et al., 2013) showed that the transition stress is only $256 \mathrm{MPa}$ at a strain rate of $4 \times 10^{-3} / \mathrm{s}$, which is much lower than the dynamic transition stress at ultra-high strain rate.

\subsection{Dynamic tensile strength}

For experiments under higher peak pressure, spallation was observed due to the interaction between the tensile waves reflected from the free surface and the release waves in the target (see Fig. 5). No spallation behavior was observed in the specimen shocked at laser power density $2.6 \mathrm{GW} / \mathrm{cm}^{2}$ where the peak pressure is estimated to be $7.5 \mathrm{GPa}$. When the shock peak pressure is low, the tension stress induced by the interaction of the release waves was insufficient to exceed the dynamic tensile strength of the NiTi alloy. Therefore a threshold peak pressure in the range of 7.5 GPa-8.6 GPa is required to induce spallation in the NiTi material. The dynamic tensile strength $\left(\sigma_{b}\right)$ can be obtained from the particle velocity profile at the free surface (Antoun et al., 2003; Davison et al., 1998),

$\sigma_{b}=\frac{1}{2} \rho_{0} C_{b} \Delta u$

where $\Delta u$ is the pull-back velocity, defined as the difference between the maximum velocity and the minimum velocity of the spallation signal, and $C_{b}$ is the body wave speed. The body wave speed $C_{b}$ can be calculated by the elastic longitudinal sound speed $\left(C_{L}^{e}\right)$ and the Poisson's ratio $v$. For uniaxial strain state, the elastic longitudinal sound speed $C_{L}^{e}$ and body wave speed $C_{b}$ can be expressed as (Meyers, 1994),

$C_{L}^{e}=\sqrt{\frac{(1-v) E}{(1+v)(1-2 v) \rho_{0}}}$

$C_{b}=\sqrt{\frac{E}{3(1-2 v) \rho_{0}}}$

where $E$ is the Young's modulus and $\rho_{0}$ is the material density. Comparing Eqs. (7) and (8), $C_{b}$ can be expressed as,

$C_{b}=\sqrt{\frac{1+v}{3(1-v)}} C_{L}^{e}$

Using the experimentally determined $C_{L}^{e}$ in this study, $C_{b}$ is determined to be $4.03 \mathrm{~km} / \mathrm{s}$. Consequently, the values of dynamic tensile strength $\left(\sigma_{b}\right)$ are determined using Eq. (6) and listed in column 12 of Table 1. 
The spallation strength $\left(\sigma_{b}\right)$ is determined to be $2.7 \mathrm{GPa}$ for peak pressure $8.6 \mathrm{GPa}$ and $3.0 \mathrm{GPa}$ for peak pressure $10.0 \mathrm{GPa}$ respectively. The determined spallation strength is close to the value $(2.3 \pm 0.1 \mathrm{GPa})$ determined by Meziere et al. (2006) with plate impact experiment if considering the uncertainty in laser shock experiment and the possible difference in terms of microstructure.

\section{Conclusion}

In this study, the dynamic deformation behavior of NiTi alloys under laser induced shock (strain rate $10^{6} \sim 10^{7} / \mathrm{s}$ ) was investigated. The free surface velocity of NiTi target shocked with a pulsed laser beam was measured with a PDV system. Experimental results showed that the characteristics of surface velocity, i.e. the number of velocity plateau, depended on the laser power density. Theoretical analysis of wave propagation in phase change material indicated that the two velocity plateaus correspond to martensitic transformation and subsequent plastic yielding of martensite phase, respectively. Based on present results, and the studies by Nemat-Nasser et al. (2005), Liao et al. (2012), and Wang et al. (2013) we concluded that there exists a critical peak pressure between $4.5 \mathrm{GPa}$ and $7.5 \mathrm{GPa}$ for the NiTi alloy to induce martensitic transformation at ultra-high strain rate of $10^{6} \sim 10^{7} / \mathrm{s}$ during laser induced shock. Also, at this ultra-high strain rate, the dynamic transition stress of the NiTi alloy is as high as $1.0 \mathrm{GPa}$, which is much higher than that obtained at quasi-static loading condition. Moreover, a peak pressure in the range of $7.5 \mathrm{GPa}-$ 8.6 GPa is required to create the spallation in the NiTi alloy at this ultra-high strain rate. The dynamic tensile strength of the NiTi alloy was determined to be $2.85 \mathrm{GPa}$ in average, slightly higher than the value determined with plate impact experiments in the literature.

\section{Acknowledgement}

The authors would like to thank the National Natural Science Foundation of China (Grant No. 11002150, 11332011, 11402277) for financial support.

\section{References}

Antoun, T., Seaman, L., Curran, D.R., Kanel, G.I., Razorenov, S.V., Utkin, A.V., 2003. Spall Fracture. Springer, New York.

Bouvet, C., Calloch, S., Lexcellent, C., 2004. A phenomenological model for pseudoelasticity of shape memory alloys under multiaxial proportional and nonproportional loadings. Eur. J. Mech. A Solid 23, 37-61.

Dai, X.Y., Tang, Z.P., Xu, S.L., Guo, Y.B., Wang, W.Q., 2004. Propagation of macroscopic phase boundaries under impact loading. Int. J. Impact. Eng. 30, 385-401.

Davison, L.W., Grady, D.E., Shahinpoor, M., 1998. High-pressure Shock Compression of Solids II. Springer, New York.
Ding, K., Ye, L., 2006. Laser Shock Peening: Performance and Process Simulation. Woodhead Publishing, Cambridge.

Dolan, D.H., 2010. Accuracy and precision in photonic doppler velocimetry. Rev. Sci. Instrum. 81, 053905.

Dolan, D.H., Jones, S.C., 2007. Push-pull analysis of photonic doppler velocimetry measurements. Rev. Sci. Instrum. 78, 076102

Fabbro, R., Fournier, J., Ballard, P., Devaux, D., Virmont, J., 1990. Physical study of laser-produced plasma in confined geometry. J. Appl. Phys. 68, 775-784.

Jensen, B.J., Gray III, G.T., Hixson, R.S., 2009. Direct measurements of the alpha-epsilon transition stress and kinetics for shocked iron. J. Appl. Phys. 105, 103502.

Jensen, B.J., Holtkamp, D.B., Rigg, P.A., Dolan, D.H., 2007. Accuracy limits and window corrections for photon doppler velocimetry. J. Appl. Phys. 101, 013523.

Johnson, J., Rohde, R., 1971. Dynamic deformation twinning in shock-loaded iron. J. Appl. Phys. 42, 4171-4182.

Kan, Q.H., Kang, G.Z., Qian, L.M., 2010. Super-elastic constitutive model considering plasticity and its finite element implementation. Acta Mech. Solida Sin. 23, 95-105

Liao, Y., Ye, C., Lin, D., Suslov, S., Cheng, G.J., 2012. Deformation induced martensite in NiTi and its shape memory effects generated by low temperature laser shock peening. J. Appl. Phys. 112, 033515.

Lin, B., Zabeen, S., Tong, J., Preuss, M., Withers, P.J., 2015. Residual stresses due to foreign object damage in laser-shock peened aerofoils: simulation and measurement. Mech. Mater. 82, 78-90.

Lubliner, J., Auricchio, F., 1996. Generalized plasticity and shape memory alloys. Int J. Solids Struct. 33, 991-1003.

Meyers, M.A., 1994. Dynamic Behavior of Materials. Wiley-Interscience, New York.

Meziere, Y.J.E., Millett, J.C.F., Bourne, N.K., 2006. Equation of state and mechanical response of NiTi during one-dimensional shock loading. J. Appl. Phys. 100, 033513.

Millett, J., Bourne, N., 2004. The shock-induced mechanical response of the shape memory alloy, NiTi. Mater. Sci. Eng. A 378, 138-142.

Montross, C.S., Wei, T., Ye, L., Clark, G., Mai, Y.-W., 2002. Laser shock processing and its effects on microstructure and properties of metal alloys: a review. Int. J. Fatigue 24, 1021-1036.

Nemat-Nasser, S., Choi, J.Y., 2005. Strain rate dependence of deformation mechanisms in a Ni-Ti-Cr shape-memory alloy. Acta Mater. 53, 449-454.

Nemat-Nasser, S., Choi, J.Y., Guo, W.G., Isaacs, J.B., 2005. Very high strain-rate response of a NiTi shape-memory alloy. Mech. Mater. 37, 287-298.

Otsuka, K., Ren, X., 2005. Physical metallurgy of Ti-Ni-based shape memory alloys. Prog. Mater. Sci. 50, 511-678.

Otsuka, K., Wayman, C.M., 1999. Shape Memory Materials. Cambridge University Press, Cambridge.

Peyre, P., Fabbro, R., 1995. Laser shock processing: a review of the physics and applications. Opt. Quant. Electron. 27, 1213-1229.

Song, H.W., Wu, X.Q., Huang, C.G., Wei, Y.P., Wang, X., 2012. Measurement of fast-changing low velocities by photonic doppler velocimetry. Rev. Sci. Instrum. 83,0733301

Strand, O.T., Goosman, D.R., Martinez, C., Whitworth, T.L., Kuhlow, W.W., 2006. Compact system for high-speed velocimetry using heterodyne techniques. Rev. Sci. Instrum. 77, 083108

Wang, X., Xia, W.G., Wu, X.Q., Wei, Y.P., Huang, C.G., 2013. Microstructure and mechanical properties of an austenite NiTi shape memory alloy treated with laser induced shock. Mat. Sci. Eng. A 578, 1-5.

Wu, X.Q., Duan, Z.P., Song, H.W., Wei, Y.P., Wang, X., Huang, C.G., 2011. Shock pressure induced by glass-confined laser shock peening: experiments, modeling and simulation. J. Appl. Phys. 110, 053112.

Wu, X.Q., Xia, W.G., Wang, X., Song, H.W., Huang, C.G., 2014. Effect of surface reflectivity on photonic doppler velocimetry measurement. Meas. Sci. Technol. 25, 055207.

Zhakhovsky, V.V., Budzevich, M.M., Inogamov, N., White, C.T., Oleynik, I.I., 2012. Single two-zone elastic-plastic shock waves in solids. AIP Con. Proc. 1426, 1227-1232. 